\title{
Is There any Time Dependant Echocardiographical Finding in Chronic Hemodialysis Patients?
}

\author{
Mohsen Abbasnezhad a, d, Hamid Tayyebi-Khosroshahi ${ }^{\mathrm{b}}$, \\ Amin Ghanbarpourc, Afshin Habibzadeh ${ }^{\mathrm{c}}$
}

\begin{abstract}
Background: Cardiac disease is the main cause of death in hemodialysis patients. In hemodialysis patients cardiovascular complications are great clinical challenge, and function, shape and left ventricle abnormalities are present in $70-80$ percent of dialysis patients. Changes in heart function occur in hemodialysis period and are effective in patient's prognosis. In this study we aim to evaluate time dependant clinical and echocardiographical findings in chronic hemodialysis patients.
\end{abstract}

Methods: In a cross-sectional study, 100 adult hemodialysis patients $(51 \%$ male and $49 \%$ female with mean age $52.13 \pm 12.69$ years) visiting dialysis unit in Imam Reza and Madani hospitals between years 2010 and 2011 were studied in group 1 (hemodialysis $\leq 6$ months), group 2 (hemodialysis for 6 months to 3 years) and group 3 (hemodialysis $\geq 3$ years). Demographic, laboratory and echocardiographic findings were compared between groups.

Results: Among demographic findings, group 3 had significantly higher diastolic blood pressure and weight gain and was older than other two groups $(\mathrm{P}<0.05)$. By increase in hemodialysis period, patients had higher blood urea nitrogen and lower serum albumin levels $(\mathrm{P}<0.05)$. Potassium level in group 2 was significantly higher than group 3 and that was higher than group 1. There was no difference between groups in left ventricular hypertrophy (LVH), left atrium dilatation, ejection fraction and mitral insufficiency. Diastolic dysfunction increased in line with increase in hemodialysis period $(\mathrm{P}=0.007)$. Hemodialysis period was higher in patients with LVH than those without $(34.80 \pm 9.2$ months versus $18.51 \pm 2.22$ months, $\mathrm{P}=0.01$ ).

Manuscript accepted for publication December 15, 2012

${ }^{a}$ Dept. of Cardiology, Cardiovascular Research Center, Tabriz

University of Medical Sciences, Tabriz, Iran

${ }^{\mathrm{b}}$ Dept. of Nephrology, Tabriz University of Medical Sciences, Tabriz, Iran

${ }^{\mathrm{c}}$ Medical Philosophy and History Research Center, Tabriz University of Medical Sciences, Tabriz, Iran

${ }^{\mathrm{d} C}$ Corresponding author: Mohsen Abbasnezhad, Cardiovascular

Research Center, Tabriz University (Medical Sciences), Golbad Ave.,

Tabriz, Iran. Email: dr_nezhad@yahoo.com

doi: http://dx.doi.org/10.4021/cr241e
Conclusions: In hemodialysis patients, diastolic dysfunction increases by the hemodialysis time (years). LVH and LA dilation also increase during time, but not significantly.

Keywords: Hemodialysis; Echocardiography; Left ventricle hypertrophy

\section{Introduction}

Cardiovascular complications are the most important cause of death in patients with end stage renal disease (ESRD) on hemodialysis treatment $[1,2]$. These patients have an increased prevalence of coronary heart disease, silent myocardial ischemia, ventricular and supraventricular disturbances in heart rhythm [3], left ventricular hypertrophy, changes in the mitral and aortic valves, and enlargement of the left atrium $[4,5]$.

Anomalies of left ventricular (LV) structure and function are very frequent among CKD patients [6]. Many data are available about patients with advanced renal dysfunction. Among patients with ESRD, nearly 15\% have systolic dysfunction, nearly $40 \%$ have heart failure and more than $70 \%$ have LVH $[7,8]$.

The diagnosis of LV abnormalities by Doppler echocardiography is an important step for the characterization of individuals with higher cardiovascular risk, estimating the prevalence of primary heart disease in a population to study its predisposing factors, prognostic impact and the effect of therapeutic interventions [9]. Echocardiography provides a non-invasive assessment of left ventricular structure and function. Echocardiography also provides information on both left ventricular geometry and left ventricular contractility. The type of left ventricular geometry may also have prognostic implications [10]. It has been shown that regression of electrocardiographic LV hypertrophy improves prognosis in the general population [11]; as well regression of LV abnormalities is associated with improved cardiac outcome in dialysis patients [12].

Cardiac function changes in time in hemodialysis pa- 
Table 1. Clinical Findings Between Three Groups

\begin{tabular}{|c|c|c|c|c|}
\hline & $\begin{array}{l}\text { Group } 1 \\
(\leq 6 \mathrm{mnt})\end{array}$ & $\begin{array}{l}\text { Group } 2 \\
(>6 \text { mnt } \leq 3 \text { yrs })\end{array}$ & $\begin{array}{l}\text { Group } 3 \\
\text { (> } 3 \text { yrs) }\end{array}$ & P value \\
\hline Age $($ mean \pm SD $)$ & $45.73 \pm 13.25$ & $52.50 \pm 12.55$ & $57.86 \pm 9.44$ & $0.005^{*}$ \\
\hline Gender (male\%) & $12(52.2 \%)$ & $25(45.5 \%)$ & $14(63.6 \%)$ & 0.35 \\
\hline Diabetics (No.) (\%) & $4(17.4 \%)$ & $9(16.4 \%)$ & $6(27.3 \%)$ & 0.53 \\
\hline Hypertensive (No.) (\%) & $3(13 \%)$ & $12(21.8 \%)$ & $7(31.8 \%)$ & 0.31 \\
\hline Hyperlipidemia (No.) (\%) & $7(30.4 \%)$ & $12(21.8 \%)$ & $10(15.5 \%)$ & 0.11 \\
\hline Current smoking (No.) (\%) & $2(8.7 \%)$ & $3(5.5 \%)$ & $2(9.1 \%)$ & ----- \\
\hline Positive family history of CAD (No.) (\%) & $4(17.4 \%)$ & $6(10.9 \%)$ & $2(9.1 \%)$ & 0.64 \\
\hline Hemodialysis time (per week) & $3.04 \pm 0.20$ & $2.78 \pm 0.41$ & $2.63 \pm 0.49$ & $0.003 *$ \\
\hline Systolic Blood pressure (mean $\pm \mathrm{SD}$ ) & $131.51 \pm 9.46$ & $128.73 \pm 9.72$ & $133.64 \pm 16.56$ & 0.21 \\
\hline Diastolic Blood pressure $($ mean \pm SD) & $84.78 \pm 9.22$ & $80.72 \pm 8.73$ & $87.72 \pm 12.22$ & $0.01^{*}$ \\
\hline Weight gain $($ mean $\pm \mathrm{SD})$ & $1.24 \pm 0.56$ & $1.09 \pm 0.23$ & $1.46 \pm 0.82$ & $0.01 *$ \\
\hline
\end{tabular}

${ }^{*} P$ is two tailed significant.

tients and diagnosing these changes could be effective in prognosis of the disease. In this study we evaluate the time dependant clinical and echocardiographical findings in chronic hemodialysis patients.

\section{Methods}

In this cross-sectional study 100 adult hemodialysis patients referring to hemodialysis ward in Imam Reza hospital and Shahid Madani hospital, Tabriz, Iran were studied. All adult patients with no known valvular heart disease and no history of previous coronary intervention were included. Informed consent was obtained from all patients, and the study was carried out following the principles of the Helsinki Declaration (Edinburgh Amendment, 2000).

Patients divided into three groups according to the time they have started hemodialysis: first group $(n=23)$ included patients within their first 6 months of hemodialysis; group two $(n=55)$ with dialysis period between 6 months and 3 years and third group $(n=22)$ included those with more than three years period of hemodialysis.

Blood pressure before dialysis and interdialytic weight gain also recorded. Cardiovascular risk factors and demographic findings were noted. Three groups were matched for gender and cardiovascular risk factors. Hypertension was accepted when pre-dialysis blood pressures reached $\mathrm{SBP} \geq 140$ $\mathrm{mmHg}$ and/or DBP $\geq 90 \mathrm{mmHg}$.

\section{Laboratory data}

Blood samples were collected pre-dialysis. Fasting serum samples were obtained in the early morning for biochemical studies. Most laboratory values including hemoglobin levels and serum levels of urea nitrogen (BUN), creatinine, electrolytes, calcium, phosphorus, total protein, albumin, total cholesterol, and triglycerides were measured by standard enzymatic procedures.

\section{Echocardiographic findings}

Echocardiography was performed using $\mathrm{M}$ mode and twodimensional ultrasonography. The protocol recommended that echocardiography be performed with the patient at dry weight, within $24 \mathrm{~h}$ after dialysis therapy in hemodialysis patients. All echocardiographic measurements were carried out according to the recommendations of the American Society of Echocardiography [13]. Echocardiographic findings including LVH, left atrial dilatation, mitral and aorta insufficiency and calcification and pleural effusion were compared 
Table 2. Laboratory Findings Between Three Groups

\begin{tabular}{|c|c|c|c|c|}
\hline & $\begin{array}{l}\text { Group } 1 \\
(\leq 6 \mathrm{mnt})\end{array}$ & $\begin{array}{l}\text { Group } 2 \\
(>6 \text { mnt } \leq 3 \text { yrs })\end{array}$ & $\begin{array}{l}\text { Group } 3 \\
\text { (>3 yrs) }\end{array}$ & P value \\
\hline Fasting blood sugar $($ mean $\pm \mathrm{SD})$ & $119 \pm 20.02$ & $109.07 \pm 22.35$ & $118 \pm 29.21$ & 0.14 \\
\hline Blood urea nitrogen $($ mean $\pm \mathrm{SD})$ & $70.78 \pm 16.72$ & $56.21 \pm 22.19$ & $64.27 \pm 19.63$ & $0.01 *$ \\
\hline Creatinine (mean $\pm \mathrm{SD})$ & $5.18 \pm 1.62$ & $5.03 \pm 1.96$ & $6.27 \pm 2.45$ & 0.05 \\
\hline Albumin $($ mean $\pm \mathrm{SD})$ & $3.59 \pm 1.21$ & $2.90 \pm 0.70$ & $2.89 \pm 0.69$ & $0.007 *$ \\
\hline Sodium $($ mean \pm SD) & $145.13 \pm 3.92$ & $144.47 \pm 3.91$ & $144.52 \pm 5.17$ & 0.81 \\
\hline Potassium (mean $\pm \mathrm{SD})$ & $4.90 \pm 0.51$ & $5.62 \pm 0.82$ & $5.40 \pm 0.85$ & $0.002 *$ \\
\hline Calcium $($ mean $\pm \mathrm{SD})$ & $7.90 \pm 0.74$ & $7.91 \pm 0.92$ & $7.47 \pm 1.34$ & 0.2 \\
\hline Phosphorus (mean $\pm \mathrm{SD}$ ) & $4.35 \pm 1.13$ & $4.57 \pm 1.41$ & $4.96 \pm 1.35$ & 0.32 \\
\hline Cholesterol (mean $\pm \mathrm{SD})$ & $144.26 \pm 31.56$ & $162.29 \pm 42.46$ & $168.05 \pm 26.71$ & 0.07 \\
\hline Hemoglobin $($ mean \pm SD) & $12.83 \pm 0.88$ & $12.28 \pm 1.68$ & $11.80 \pm 1.96$ & 0.1 \\
\hline
\end{tabular}

${ }^{*} \mathrm{P}$ is two tailed significant.

between groups. The echocardiographic readings were performed on all patients by the same echocardiographist.

\section{Statistical analysis}

Continuous data with normal distribution are given as mean \pm standard deviation, otherwise as median, one-Way ANOVA test for testing the significance of mean for independent continuous scale data, Chi-square or Fisher exact test for testing the significance of percentages. A P value $<0.05$ was considered significant. Statistical analyses were performed using the Statistical Package for Social Sciences, version 13.0 (SPSS, Chicago, Illinois).

\section{Results}

Clinical data of the three patient groups are shown in Table 1. The three groups were comparable for gender, prevalence of diabetes, hypertension, hyperlipidemia and smoking, cardiovascular disease familial history, and hemodialysis period; the groups differed regarding age, which was significantly higher in third group $(\mathrm{P}<0.005)$. Diastolic blood pressure as well as interdialytic weight gain was significantly higher in third group than two other groups (both $\mathrm{P}=0.01$ ).

FBS, creatinine, sodium, calcium, phosphorus, cholesterol and hemoglobin levels were comparable between three groups (Table 2). BUN and albumin levels significantly were higher and potassium levels were lower in first group $(\mathrm{P}=$ 0.01 and $\mathrm{P}=0.007, \mathrm{P}=0.002$ respectively).

Table 3 shows echocardiographic findings between groups. LVEF was reduced by increase in dialysis period; LVH and LA dilatation as well as mitral insufficiency was higher in patients with higher period of dialysis; however these differences was not significant $(\mathrm{P}=\mathrm{NS})$. Other parameters were comparable between groups. Mitral calcification, aortic insufficiency and aortic calcification prevalence was $<$ $5 \%$ so the results were not compared between groups.

Mean dialysis period in patients with and without LVH was $34.80 \pm 9.62$ and $18.51 \pm 2.22$ months; Patients with LVH had significantly longer hemodialysis period $(\mathrm{P}=0.01)$. Grade of diastolic dysfunction significantly increased by the dialysis period $(\mathrm{P}=0.007)$, as in diastolic dysfunction grade IV mean hemodialysis period was more than 2 years (Fig. 1).

\section{Discussion}

Although hemodialysis (HD) keeps alive patients with endstage renal disease (ESRD), the survival of these patients is still reduced [14, 15], and despite technologic advances, it has not improved much over the last two decades [1, 16]. Cardiovascular diseases are the most important cause of mortality in HD patients, accounting for about $50 \%$ of deaths $[1,14]$, rendering the rate of cardiovascular mortality in these patients 20 times greater compared with that in the 
Table 3. Echocardiographic Findings Between Groups

\begin{tabular}{|c|c|c|c|c|c|}
\hline & $\begin{array}{l}\text { Group } 1 \\
(\leq 6 \mathrm{mnt})\end{array}$ & $\begin{array}{l}\text { Group } 2 \\
(>6 \text { mnt } \leq 3 \text { yrs })\end{array}$ & $\begin{array}{l}\text { Group } 3 \\
\text { (>3 yrs) }\end{array}$ & All & P value \\
\hline $\mathrm{LVEF} \leq 50 \%($ No. $)(\%)$ & $5(21.7 \%)$ & $14(25.5 \%)$ & $9(40.9 \%)$ & $28 \%$ & 0.29 \\
\hline LVH (No.) (\%) & $4(17.4 \%)$ & $15(27.3 \%)$ & $7(31.8 \%)$ & $26 \%$ & 0.51 \\
\hline LA dilation (No.) (\%) & $4(17.4 \%)$ & $15(27.3 \%)$ & $7(31.8 \%)$ & $26 \%$ & 0.51 \\
\hline $\begin{array}{l}\text { Diastolic dysfunction } \\
\text { (grade III, IV) (No.) (\%) }\end{array}$ & $1(4.3 \%)$ & $15(27.3 \%)$ & $6(27.3 \%)$ & $22 \%$ & 0.06 \\
\hline Mitral insufficiency (No.) (\%) & $13(56.5 \%)$ & $36(65.5 \%)$ & $18(81.8 \%)$ & $67 \%$ & 0.18 \\
\hline Mitral calcification (No.) (\%) & $0 \%$ & $3(5.5 \%)$ & $0 \%$ & $3 \%$ & ---- \\
\hline Aortic Insufficiency (No.) (\%) & $0 \%$ & $2(3.6 \%)$ & $1(4.5 \%)$ & $3 \%$ & ---- \\
\hline Aortic calcification (No.) (\%) & $0 \%$ & $1(1.8 \%)$ & $0 \%$ & $1 \%$ & ---- \\
\hline Pericardial effusion (No.) (\%) & $4(17.4 \%)$ & $24(43.6 \%)$ & $7(31.8 \%)$ & $35 \%$ & 0.08 \\
\hline
\end{tabular}

LVEF: Left ventricular ejection fraction; LVH: Left Ventricle Hypertrophy; LA: Left atrium.

general population [17].

Left ventricular hypertrophy (LVH) and left ventricu- lar systolic and diastolic dysfunction are the most common cardiovascular abnormalities and associated with increased

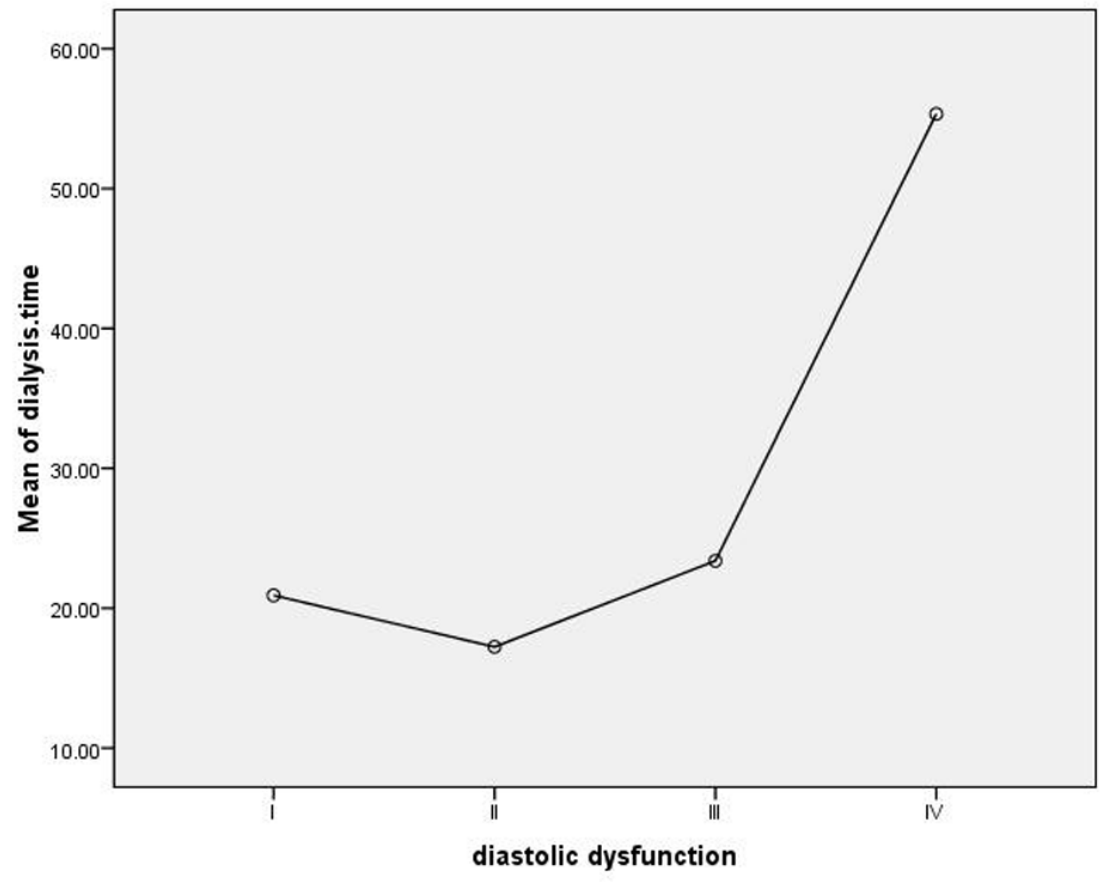

Figure 1. Mean hemodialysis period. 
morbidity and mortality in patients with ESRD [18]. In one study higher LVH, left ventricular diastolic dysfunction, valvular disease and calcification were reported in hemodialysis patients [19].

In this study we aim to compare time dependant echocardiographical findings in chronic hemodialysis patients in three different time periods. In our study of 100 hemodialysis patients, $26 \%$ had LVH and LA dilatation. Severe diastolic dysfunction was observed in $22 \%$. Foley et al [7] studied the echocardiographic risk factors for the development of heart failure in patients who underwent echocardiography at baseline and at one year after starting dialysis therapy. In their study systolic dysfunction was observed in $15 \%$, LA dilatation in $32 \%$ and $\mathrm{LVH}$ in $74 \%$ of patients; these were higher from our study.

In another study among patients with more than 3 months of hemodialysis, deFilippi et al [20] reported LVH in $46 \%$ of patients. In our study $2 / 3$ of patients were under dialysis less than 3 years; a period that various treatments are used to prevent disease progression and severe complications. The difference between groups could be due to strategies to regulate blood pressure levels of the patients, treatment of anemia and other metabolic disorders during the HD period and the prevention of weight gain and hypervolemia, the risk factors related to LV function change [21, 22].

At a later stage longstanding haemodialysis is associated with advanced cardiac dysfunction [12, 23]. In patients with long time hemodialysis, LVH exist in three fourth of them and usually accompany by LA dilatation and LV dysfunction [7]. Also, heart chambers dilatation happens in long with compensated hypertrophy in time in dialysis patients [20].

Kocinaj and coworkers [24] reported that LA dilation was higher by increase in years of hemodialysis. Borsboom et al [25] reported high incidence of LVH and diastolic dysfunction mostly in patients being under dialysis for more than 3 years. However, in current study although not significant, LVH, LA dilation, reduced ejection fraction and mitral insufficiency prevalence were higher by increase in the time under hemodialysis. However, diastolic dysfunction significantly increased in time as severe diastolic dysfunction was higher in patients with more than 2 years of dialysis and patients with LVH had significantly longer hemodialysis period. Likewise, in the study of Duran and coworkers [26] LV systolic functions, LV diameters, LV mass index, left atrium size, and RV diastolic functions were not statistically different after long-term HD treatment.

\section{Conclusion}

In hemodialysis patients, diastolic dysfunction increases by the hemodialysis time (years). LVH and LA dilation also increase during time, but not significantly. These findings could be due to a limitation; most patients were between 6 months to 3 years of hemodialysis which could affect our results.

\section{Acknowledgment}

This research was financially supported by Vice Chancellor for Research, Tabriz University of Medical Sciences, Iran. The authors are indebted to Cardiovascular Research Center, Tabriz University of Medical Sciences, Tabriz, Iran for its support.

\section{References}

1. Raine AE, Margreiter R, Brunner FP, Ehrich JH, Geerlings $\mathrm{W}$, Landais $\mathrm{P}$, Loirat $\mathrm{C}$, et al. Report on management of renal failure in Europe, XXII, 1991. Nephrol Dial Transplant. 1992;7 (Suppl 2):7-35.

2. Jardine AG, McLaughlin K. Cardiovascular complications of renal disease. Heart. 2001;86(4):459-466.

3. Kocheril AG. Arrhythmia issues in patients with renal disease. Semin Nephrol. 2001;21(1):57-65.

4. Atar I, Konas D, Acikel S, Kulah E, Atar A, Bozbas H, Gulmez O, et al. Frequency of atrial fibrillation and factors related to its development in dialysis patients. Int $\mathrm{J}$ Cardiol. 2006;106(1):47-51.

5. Das M, Aronow WS, McClung JA, Belkin RN. Increased prevalence of coronary artery disease, silent myocardial ischemia, complex ventricular arrhythmias, atrial fibrillation, left ventricular hypertrophy, mitral annular calcium, and aortic valve calcium in patients with chronic renal insufficiency. Cardiol Rev. 2006;14(1):14-17.

6. Nardi E, Palermo A, Mule G, Cusimano P, Cottone S, Cerasola G. Left ventricular hypertrophy and geometry in hypertensive patients with chronic kidney disease. J Hypertens. 2009;27(3):633-641.

7. Foley RN, Parfrey PS, Harnett JD, Kent GM, Martin CJ, Murray DC, Barre PE. Clinical and echocardiographic disease in patients starting end-stage renal disease therapy. Kidney Int. 1995;47(1):186-192.

8. Levin A, Thompson CR, Ethier J, Carlisle EJ, Tobe S, Mendelssohn D, Burgess E, et al. Left ventricular mass index increase in early renal disease: impact of decline in hemoglobin. Am J Kidney Dis. 1999;34(1):125-134.

9. Yamada H, Goh PP, Sun JP, Odabashian J, Garcia MJ, Thomas JD, Klein AL. Prevalence of left ventricular diastolic dysfunction by Doppler echocardiography: clinical application of the Canadian consensus guidelines. J Am Soc Echocardiogr. 2002;15(10 Pt 2):1238-1244.

10. Koren MJ, Devereux RB, Casale PN, Savage DD, Laragh JH. Relation of left ventricular mass and geometry to morbidity and mortality in uncomplicated essential hypertension. Ann Intern Med. 1991;114(5):345-352.

11. Levy D, Salomon M, D’Agostino RB, Belanger AJ, Kannel WB. Prognostic implications of baseline electrocardiographic features and their serial changes in subjects with left ventricular hypertrophy. Circulation. 
1994;90(4):1786-1793.

12. Foley RN, Parfrey PS, Kent GM, Harnett JD, Murray DC, Barre PE. Serial change in echocardiographic parameters and cardiac failure in end-stage renal disease. $\mathrm{J}$ Am Soc Nephrol. 2000;11(5):912-916.

13. Cheitlin MD, Alpert JS, Armstrong WF, Aurigemma GP, Beller GA, Bierman FZ, Davidson TW, et al. ACC/ AHA Guidelines for the Clinical Application of Echocardiography. A report of the American College of Cardiology/American Heart Association Task Force on Practice Guidelines (Committee on Clinical Application of Echocardiography). Developed in collaboration with the American Society of Echocardiography. Circulation. 1997;95(6):1686-1744.

14. Morton CC. U.S. dialysis survival strategy. Ann Intern Med. 1998;128(6):514-516.

15. Eknoyan G. On the epidemic of cardiovascular disease in patients with chronic renal disease and progressive renal failure: a first step to improve the outcomes. Am J Kidney Dis. 1998;32(5 Suppl 3):S1-4.

16. De-Lima JJ, da-Fonseca JA, Godoy AD. Dialysis, time and death: comparisons of two consecutive decades among patients treated at the same Brazilian dialysis center. Braz J Med Biol Res. 1999;32(3):289-295.

17. Lindner A, Charra B, Sherrard DJ, Scribner BH. Accelerated atherosclerosis in prolonged maintenance hemodialysis. N Engl J Med. 1974;290(13):697-701.

18. Scharer K, Schmidt KG, Soergel M. Cardiac function and structure in patients with chronic renal failure. Pediatr Nephrol. 1999;13(9):951-965.

19. Arjona Barrionuevo JD, Gonzales Vargas-Machuca MF, Gomez Pulido F, Gil Sacaluga L, Gentil Govantes
MA, Martinez-Martinez A. Transthoracic echocardiographic findings in patients with chronic kidney disease awaiting kidney transplantation. Transplant Proc. 2010;42(8):3123-3125.

20. deFilippi CR, Thorn EM, Aggarwal M, Joy A, Christenson RH, Duh SH, Jeudy J, et al. Frequency and cause of cardiac troponin $\mathrm{T}$ elevation in chronic hemodialysis patients from study of cardiovascular magnetic resonance. Am J Cardiol. 2007;100(5):885-889.

21. Alpert MA. Cardiac performance and morphology in end-stage renal disease. Am J Med Sci. 2003;325(4):168178.

22. Meeus F, Kourilsky O, Guerin AP, Gaudry C, Marchais SJ, London GM. Pathophysiology of cardiovascular disease in hemodialysis patients. Kidney Int Suppl. 2000;76:S140-147.

23. Foley RN, Parfrey PS, Kent GM, Harnett JD, Murray DC, Barre PE. Long-term evolution of cardiomyopathy in dialysis patients. Kidney Int. 1998;54(5):1720-1725.

24. Kocinaj D, Gashi M, Berisha M, Kocinaj A, Ramadani N, Korca H. Echocardiographic assessment of left atrial size in patients with end-stage renal disease. Cardiovasc J Afr. 2009;20(3):183-186.

25. Borsboom H, Smans L, Cramer MJ, Kelder JC, Kooistra MP, Vos PF, van Jaarsveld BC. Long-term blood pressure monitoring and echocardiographic findings in patients with end-stage renal disease: reverse epidemiology explained? Neth J Med. 2005;63(10):399-406.

26. Duran M, Unal A, Inanc MT, Kocyigit I, Oguz F, Ocak A, Ozdogru I, et al. Hemodialysis does not impair ventricular functions over 2 years. Hemodial Int. 2011;15(3):334-340. 